\title{
Health-related Quality of Life in Intermediate- or High-risk Patients Treated With Radical External Radiotherapy and Adjuvant Docetaxel for Localized Prostate Cancer: A Randomized, Phase III SPCG-13 Study
}

\author{
MIIKKA LEHTONEN ${ }^{1}$, JORMA SORMUNEN ${ }^{1,2}$, MARIE HJÄLM-ERIKSSON $^{3}$, \\ CAMILLA THELLENBERG-KARLSSON ${ }^{4}$, TEPPO HUTTUNEN $^{5}$, \\ CLAES GINMAN $^{6}$ and PIRKKO-LIISA KELLOKUMPU-LEHTINEN ${ }^{1,7}$ \\ On Behalf of the Investigators of the Scandinavian Prostate Cancer Group Study No 13 \\ ${ }^{1}$ Tampere University, Faculty of Medicine and Health Technology, Tampere, Finland; \\ ${ }^{2}$ Docrates Cancer Center, Helsinki, Finland; \\ ${ }^{3}$ Department of Surgery Capio ST: Görans Hospital and Department of Oncology and Pathology, \\ Karolinska Institutet, Stockholm, Sweden; \\ ${ }^{4}$ Department of Radiation Sciences, Oncology, Umeå University Hospital, Umeå, Sweden; \\ ${ }^{5}$ EstiMates, Turku, Finland; \\ ${ }^{6}$ Karlstad Central Hospital, Karlstad, Sweden; \\ ${ }^{7}$ Tampere University Hospital, Tampere, Finland
}

\begin{abstract}
Background/Aim: The goal of this study was to investigate whether health-related quality of life (HRQoL) was affected in patients with high-or intermediate-risk localized prostate cancer treated with docetaxel following radiation therapy (RT). Patients and Methods: A total of 376 patients treated with $R T$ and androgen deprivation were randomized to receive 6 cycles of docetaxel $75 \mathrm{mg} / \mathrm{m}^{2}(\mathrm{~N}=188$, Arm A) or surveillance $(N=188$, Arm B). FACT-P HRQoL questionnaires were gathered at baseline, six months and 1,2 and 4 years after randomization. The data were analysed using analysis of covariance. Results: FACT-P scores decreased in Arm A at the end of treatment and remained unchanged in Arm B $(p<0.0001)$. The HRQoL scores in Arm A matched Arm B in the 1-year follow-up $(p=0.0528)$ and remained similar in further follow-up. Conclusion: Docetaxel transiently decreased HRQoL during chemotherapy but not after treatment for up to four years of follow-up.
\end{abstract}

Adjuvant treatment with docetaxel for local prostate cancer (PC) has been studied in few prospective randomized trials

This article is freely accessible online.

Correspondence to: Miikka Lehtonen, MD, Heikkiläntie 1 C 39, 00210 Helsinki, Finland. E-mail: miikka.m.lehtonen@tuni.fi

Key Words: Radiotherapy, prostate cancer, quality of life, docetaxel. after radical prostatectomy (RP) and radiotherapy (RT) during the past two decades (1-4). After local treatment, the risk of biochemical recurrence for a high-risk disease is approximately $50 \%$ at five years (5-9). A docetaxel-based treatment has been shown to increase survival in both hormone-naïve and castration-resistant metastatic prostate cancer (10-14). In early-stage breast cancer, an adjuvant taxane-based regimen has been accepted as standard treatment over the past twenty years (15-17).

The Scandinavian Prostate Cancer Group (SPCG) initiated two prospective open-label, randomized trials, SPCG-12 and SPCG-13, to evaluate a possible benefit of docetaxel as adjuvant treatment after local curative treatment in localized high- or intermediate-risk prostate cancer. In the SPCG-12 trial, the patients were randomized to receive six cycles of docetaxel without androgen-deprivation therapy (ADT) or surveillance after RP and in the SPCG-13 they received six cycles of docetaxel with ADT or surveillance with ADT after curativeintent external beam radiotherapy (EBRT) without continuous prednisone. ADT treatment was continued for three months and was ended before the beginning of docetaxel treatment. The adjuvant docetaxel did not improve biochemical progressionfree survival (BPFS) in either of the trials $(2,3)$. In the NRG Oncology RTOG 0521 trial, which included only high-risk patients after EBRT, docetaxel with ADT improved not only BPFS but also metastasis-free survival (MFS) and overall survival (OS) (1). In the GETUG-12 trial, BPFS was improved with a combination of docetaxel and estramustine, but MFS 
Table I. Baseline characteristics of included patients.

\begin{tabular}{lcc}
\hline Factor & Adjuvant treatment with docetaxel $(\mathrm{N}=180)$ & Surveillance $(\mathrm{N}=183)$ \\
\hline Age $(\mathrm{yrs})$, median $(\mathrm{IQR})$ & $67(63.5-70)$ & $67(63-71)$ \\
PSA before RT $(\mathrm{ng} / \mathrm{ml})$, median $(\mathrm{IQR})$ & $14.1(7.8-28.0)$ & $14.1(7.1-26.0)$ \\
PSA after RT (ng/ml), median (IQR) & $0.49(0.15-2.70)$ & $0.60(0.12-1.75)$ \\
T-stage T2/T3 (\%) & $26 / 74$ & $25 / 75$ \\
Gleason 7/8/9-10 & $56 / 25 / 19$ & $50 / 25 / 25$ \\
WHO status 0/1 $(\%)$ & $92 / 8$ & $95 / 5$ \\
\hline
\end{tabular}

IQR: Interquartile range; PSA: prostate-specific antigen; RT: radiotherapy; WHO: World Health Organization.

was not $(4,18)$. Currently, we cannot exclude the possibility that docetaxel could be beneficial in some subgroups of early prostate cancer after EBRT.

If docetaxel is to be considered in the treatment for local PC after EBRT, it is important to know how it affects the quality of life (QoL) of the patient. The reporting of QoL results after treatment of a local PC with docetaxel has been sparse. In the STAMPEDE trial, which included high-risk PC patients with rising PSA values, the combination of docetaxel and ADT after either EBRT or RP did not decrease patients' QoL compared to ADT alone (9). In the GETUG 12 trial, QoL was decreased at three months but not at one year of follow-up (4). The goal of this study was to investigate whether health-related quality of life (HRQoL) was affected by adjuvant docetaxel given after radical RT in the randomized SPCG-13 trial.

\section{Patients and Methods}

The main inclusion criteria for the SPCG-13 trial were men between 18 and 75 years, World Health Organization (WHO) performance status $0-1$, and histologically confirmed adenocarcinoma of the prostate within 12 months before randomization. Additionally, one of the following features was required: T2 with Gleason $7(4+3)$ and prostate-specific antigen (PSA) level between 10-70 ng/ml, T2 with Gleason 8-10 and PSA under $70 \mathrm{ng} / \mathrm{ml}$, or any T3 tumours. Thus, all of the SPCG-13 patients belonged to an intermediate- or high-risk group according to the National Comprehensive Cancer Network $(\mathrm{NCCN})$ guidelines $(8)$. Other key inclusion and exclusion criteria were described in detail in our previous publication (2). Every patient signed an informed consent form before they were enrolled in the study. Before signing, they had the possibility to ask questions and consider their participation. The trial was approved by the ethics committee of Tampere University Hospital. The trial identifier at the Clinical Trials website (https://clinicaltrials.gov) is NCT00653848.

The primary endpoint of the trial was BPFS. The secondary endpoints were PSA doubling time, safety (using CTCAE version 3.0, https://ctep.cancer.gov/), MFS, OS and QoL. QoL was measured by version 4 of the Functional Assessment of Cancer Therapy - Prostate (FACT-P) questionnaire, which is a validated tool for the evaluation of QoL in men with prostate cancer $(19,20)$.

The FACT-P questionnaire includes 27 general cancer-specific questions divided into four subscales (physical well-being, social/family well-being, emotional well-being, and functional well-being) as well as
12 prostate cancer-specific items in this prostate cancer subscale to assess function during the previous 7 days. The FACT-P total score is a summary of general subscale scores and prostatic cancer-specific subscale scores, where each item is rated on a Likert-type scale of 0-4 ( $0=$ not at all, $1=$ a little bit, $2=$ somewhat, $3=$ quite a bit, and $4=$ very much), for which higher scores indicate better HRQoL.

A total of 378 patients who met the inclusion and exclusion criteria were randomized after completion of RT to six courses of docetaxel (Arm A, N=188) or surveillance (Arm B, N=188). The randomization took place between May 2007 and August 2012. All patients received ADT (luteinizing hormone-releasing hormone (LHRH) analogue), for nine months starting three months before RT. Arm A additionally received six courses of docetaxel, $75 \mathrm{mg} / \mathrm{m}^{2}$ every three weeks starting three months after completion of RT. RT was 3-D conformal RT or intensity-modulated RT. In addition, a boost of brachytherapy was allowed. Total tumour dose had to be $\geq 74$ Gy.

In Arm A 177 patients were followed more than three months. 171 patients completed follow-up. Eight patients withdrew consent, 4 patients were lost to follow-up, 4 patients were excluded due to protocol violations, and one patient had no follow-ups. In Arm B (surveillance), all 188 patients were followed for more than three months. A total of 186 patients completed the follow-up, one was lost to follow-up, and one withdrew consent (2). This HRQoL analysis included 183 patients in Arm A and 180 patients in Arm B who completed the FACT-P questionnaire at baseline.

FACT-P QoL questionnaires were gathered at baseline, during and after docetaxel treatment and yearly in the follow-ups at 1 year, 2 years and 4 years after treatment) in both groups and analysed using an analysis of covariance (ANCOVA) model adjusted for baseline. The calculations were performed by a statistician using SAS version 9.4 statistical software. The clinically significant difference was defined as the minimum 6-point difference in the total FACT-P score and the minimum 2-point difference in the FACT-P subdomains, based on the evidence by Cella et al. (21).

\section{Results}

The baseline characteristics are shown in Table I. A total of $147(78.2 \%)$ patients completed all six cycles of docetaxel in $\operatorname{arm} \mathrm{A}$. The mean age was 66.2 years (range=47-75) in arm $\mathrm{A}$ and 66.4 years (range=46-76) in arm B. The median follow-up was 59.4 months (range=1-111 months).

The total HRQoL scores at baseline did not differ between arms. In Arm A (docetaxel group, $\mathrm{N}=177$ ), the mean total 
Table II. Total scores from FACT-P questionnaires.

\begin{tabular}{|c|c|c|c|c|c|c|}
\hline Time & & $\mathrm{N}$ & Mean & SD & $95-\% \mathrm{CI}$ & $p$-Value \\
\hline \multirow[t]{2}{*}{ Baseline } & Arm A (docetaxel) & 177 & 119.0 & 18.86 & [116.2-121.7] & $0.701(\mathrm{NS})$ \\
\hline & Arm B (surveillance) & 180 & 118.2 & 18.14 & [115.5-120.8] & \\
\hline \multirow[t]{2}{*}{ Six months } & Arm A (docetaxel) & 120 & 116.6 & 14.0 & [114.1-119.1] & $<0.0001$ \\
\hline & Arm B (surveillance) & 122 & 123.7 & 13.4 & {$[121.3-126.1]$} & \\
\hline \multirow[t]{2}{*}{1 year } & Arm A (docetaxel) & 91 & 123.0 & 13.88 & [120.2-125.9] & $0.344(\mathrm{NS})$ \\
\hline & Arm B (surveillance) & 85 & 125.0 & 13.6 & [122.1-127.9] & \\
\hline \multirow[t]{2}{*}{2 years } & Arm A (docetaxel) & 99 & 124.4 & 14.14 & [121.6-127.2] & $0.097(\mathrm{NS})$ \\
\hline & Arm B (surveillance) & 104 & 127.7 & 13.6 & {$[125.0-130.4]$} & \\
\hline \multirow[t]{2}{*}{4 years } & Arm A (docetaxel) & 91 & 125.0 & 13.89 & [122.1-127.8] & $0.764(\mathrm{NS})$ \\
\hline & Arm B (surveillance) & 103 & 125.6 & 14.1 & [122.8-128.3] & \\
\hline
\end{tabular}

SD: Standard deviation, CI: confidence interval, NS: not significant.

score from the FACT-P questionnaire was 119.0 with a $95 \%$ confidence interval $(\mathrm{CI})=116.2-121.7$, while it was 118.2 (95\% CI=115.5-120.8) in Arm B (surveillance, $\mathrm{N}=180$ ).

At the end of treatment ( 24 weeks or earlier if docetaxel had to be halted prematurely), the mean HRQoL score significantly declined in Arm A to 116.6 (as estimated with the ANCOVA model, adjusting for baseline values), while it was 123.7 in Arm B ( $p<0.0001$, ANCOVA model for difference between groups). This difference ( -7.1 points) was also clinically significant.

However, at one year, the total HRQoL scores did not differ between arms (123.0 vs. 125.0, respectively), as estimated with the ANCOVA model, $(p=0.344)$ and remained at the same level in both arms during subsequent follow-ups (Figure 1). All $p$-values and 95\%CI are listed in Table II.

A clinically significant decline in HRQoL scores during treatment with docetaxel in Arm A was seen in two domains: functional (difference -2.43 points, $p<0.0001$ ) and physical $(-2.89$ points, $p<0.0001)$. A statistically significant difference was also found in the prostate-specific subdomain $(-1.78$, $p=0.015$ ), but this did not reach the threshold of clinical significance. Graphs for all subcategories are shown in Figure 2.

\section{Discussion}

Our results show that docetaxel treatment decreases HRQoL during chemotherapy, but the effect is temporary, and no difference in HRQoL can be seen after one year. Furthermore, the decline in HRQoL is limited to the physical and functional domains in FACT-P, and differences in other domains (social, emotional, or prostate-specific categories) were not observed even during the treatment.

Our results are in line with those reported in the STAMPEDE and GETUG-12 trials $(9,18)$. In the STAMPEDE trial, which included only high-risk patients with rising PSA, QoL similarly decreased in the docetaxel group (with ADT) during treatment compared to the surveillance group (only ADT), but had recovered by the first follow-up in 9 months, and this persisted in the second follow-up in 1 year (9). In the GETUG-12 trial, docetaxel was given for high-risk local PC in combination with estramustine and ADT or ADT only (4). GETUG-12 did not use the FACT-P questionnaire, but EORTC QLQC-30 (4). QoL was worse at 3 months, but no difference was seen at 1 year (4). Statistically significant differences were seen at 3 months in global health status, fatigue, role functioning and social functioning (4). Because the questionnaire was different in the GETUG-12, the results of our study are not directly comparable, but our study showed no decline in the social subscale. Both studies used similar treatment plans (6 cycles, 3 -week cycle), but the dosage of docetaxel was slightly lower $\left(70 \mathrm{mg} / \mathrm{m}^{2}\right)$ than in our study $(4,9)$.

Our study had several strengths. This was a randomized, prospective clinical trial conducted in two very similar Nordic countries with relatively low margins for bias. Our follow-up time (up to almost 5 years) was longer than in the STAMPEDE and GETUG-12 trials, where QoL results were reported for only one year. Thus, our results demonstrated that HRQoL is not affected due to the possible long-term toxicity of adjuvant docetaxel after the curative intent EBRT for at least four years. This was a multicentre study with 11 hospitals from Sweden and Finland, which means that sample bias was also low. To the best of our knowledge, this is the largest report of QoL results for docetaxel treatment for early local PC after radical RT.

Some limitations can be identified as well. Double blinding might have been used in this setting. However, the use of intravenous placebo is considered ethically questionable in academic oncological studies because of the risk of toxicity, infusion-related decline in QoL and because otherwise wellperformed trials are considered statistically adequate (22). Placebo was not used either in comparable NRG Oncology RTOG 0521, STAMPEDE or GETUG-12 trials $(1,4,9)$. According to the declaration of Helsinki of World Medical Association (WMA), the use of placebo cannot subject patient to a risk of serious or irreversible harm (23). 


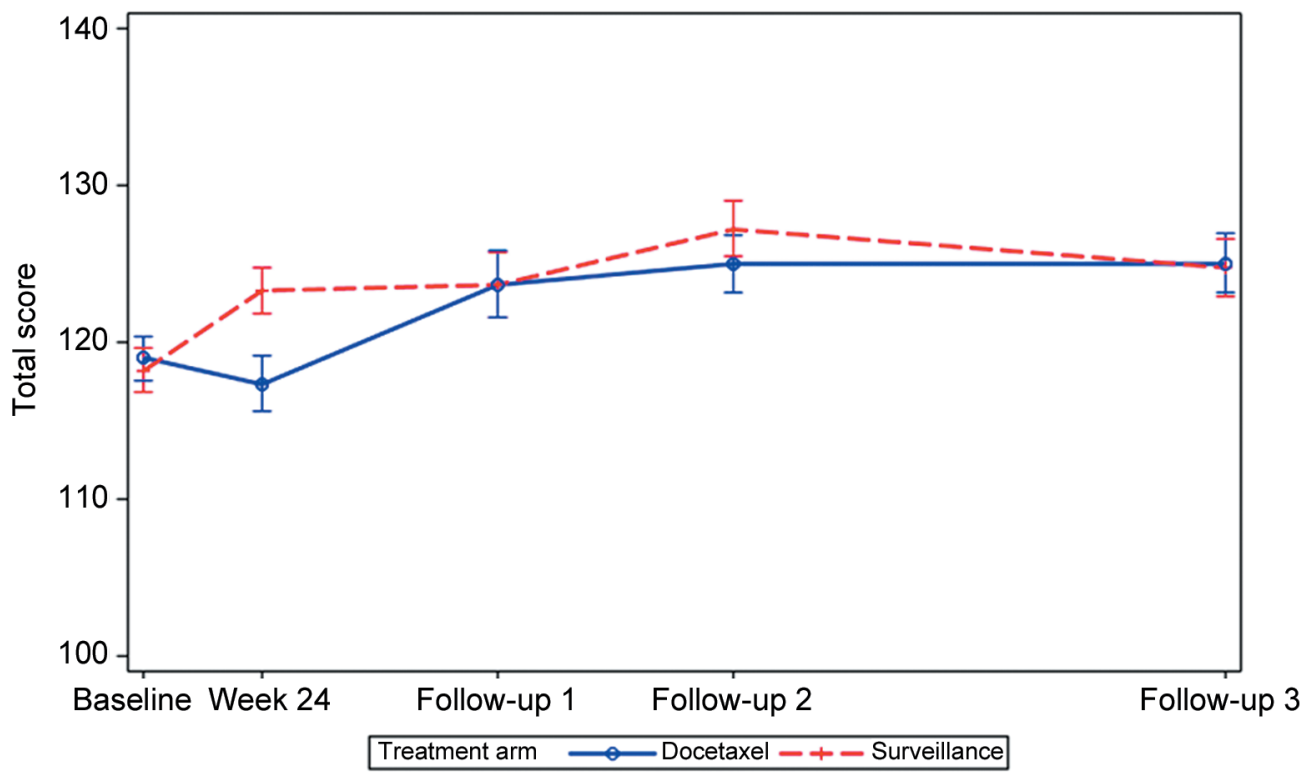

Figure 1. Quality of life total scores in the SPCG-13 trial. The FACT-P forms were collected at 6 months (the end of scheduled treatment) and follow-ups at 1, 2 and 4 years. There was a significant difference favouring surveillance at week 24, but no difference in subsequent follow-ups.

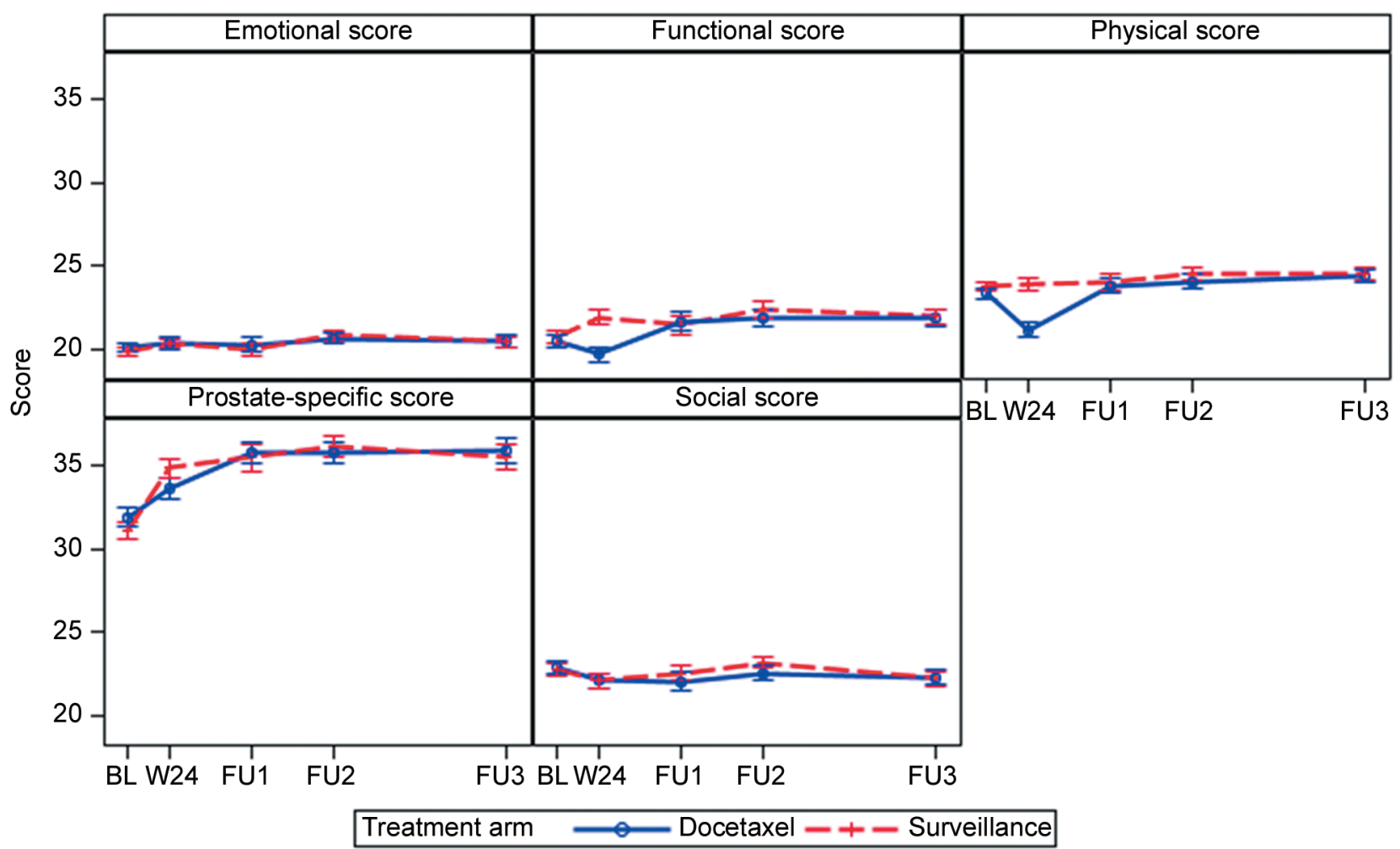

Figure 2. Quality of Life Sub-Scores in the SPCG-13 trial. The FACT-P forms were at 6 months (the end of scheduled treatment) and follow-ups at 1,2 and 4 years. The decline in HRQoL in docetaxel group at week 24 was seen only in functional and physical well-being. BL: Baseline; W24: week 24; FU: follow-up. 
The statistical method used was an ANCOVA-model, which can be considered inferior compared to the mixed model approaches if there are a significant number of missing data points (24). The decision for the ANCOVA-model was made by the statistician of the team based on the features of the data. Our results do not differ from the STAMPEDE trial, which used a mixed model (9). ANCOVA yields similar results to the mixed model, when missingness is $40-50 \%$ and has higher power with low missingness (20-40\%) (25). Missingness exceeded $50 \%$ only in one time-point (1-year control in Arm $\mathrm{B}$ ), and the 2-point difference in total FACT-P score mean is clearly unsignificant regardless of the model. On the other hand, missingness was under $30 \%$ at six months, which means that ANCOVA was superior to the mixed model at this timepoint. We lost more patients during follow-up in the treatment arm compared to the surveillance arm due to consent withdrawals, protocol violations or unattendance. It is plausible that the difference is related to the QoL factors and should be considered in the interpretation of the results.

In conclusion, adjuvant docetaxel after EBRT causes a transient decline in HRQoL during chemotherapy, with a progressive recovery to the HRQoL level of the control arm at one year. As the results from clinical trials have been conflicting, more research is needed to determine whether docetaxel is beneficial or not in men with high-risk local PC.

\section{Conflicts of Interest}

Marie Hjälm-Eriksson is a member of the advisory board of Bayer. Camilla Thellenberg-Karlsson: Speaker's fee: Janssen.

\section{Author's Contributions}

M.L. and J.S.: Writing of the article and the interpretation of statistical data, with ML being the primary writer and JS providing commentary. M. H-E., C. T-K.: acquisition of data, revision, study design. T.H.: statistical analysis, study design, writing (methodology). C.G.: study design, acquisition of data. P-L. K-L.: design, data interpretation, revision, study design, data acquisition, supervision. All Authors accepted the final manuscript.

\section{Acknowledgements}

We would like to thank all the investigators, study coordinators and nurses within the SPCG-13 participating centres: Karolinska University Hospital, Uppsala University Hospital, Örebro University Hospital, Karlstad, Sundsvall, Eskilstuna, Växjö and Jönköping Hospitals in Sweden and Tampere University Hospital, Hospitals in Lahti and Seinäjoki in Finland. We would also like to thank all patients who participated in the SPCG-13 trial, their families and Sanofi for their financial contribution to the SPCG-13 trial. The SPCG-13 investigator-sponsored trial received funding from Sanofi. This study was also partly supported by the Competitive State Research Financing of the Expert Responsibility area of Tampere University Hospital. The funders had no impact on the study design, collection of data, data analysis, interpretation of results or contents of the article.

\section{References}

1 Rosenthal SA, Hu C, Sartor O, Gomella LG, Amin MB, Purdy J, Michalski JM, Garzotto MG, Pervez N, Balogh AG, Rodrigues GB, Souhami L, Reaume MN, Williams SG, Hannan R, Horwitz EM, Raben A, Peters CA, Feng FY, Shipley WU and Sandler HM: Effect of chemotherapy with docetaxel with androgen suppression and radiotherapy for localized high-risk prostate cancer: The randomized Phase III NRG oncology RTOG 0521 trial. J Clin Oncol 37(14): 1159-1168, 2019. PMID: 30860948. DOI: $10.1200 / J C O .18 .02158$

2 Kellokumpu-Lehtinen PL, Hjälm-Eriksson M, ThellenbergKarlsson C, Åström L, Franzen L, Fransson AS, Leskinen MJ, Zeke M, Huttunen T, Ginman C and Investigators of the Scandinavian Prostate Cancer Study No. 13: Docetaxel versus surveillance after radical radiotherapy for intermediate- or highrisk prostate cancer-results from the prospective, randomised, open-label Phase III SPCG-13 trial. Eur Urol 76(6): 823-830, 2019. PMID: 31443961. DOI: 10.1016/j.eururo.2019.08.010

3 Ahlgren GM, Flodgren P, Tammela TLJ, Kellokumpu-Lehtinen P, Borre M, Angelsen A, Iversen JR, Sverrisdottir A, Jonsson E, Sengelov L and Investigators of the Scandinavian Prostate Cancer Study Number 12: Docetaxel versus surveillance after radical prostatectomy for high-risk prostate cancer: Results from the prospective randomised, open-label Phase 3 Scandinavian Prostate Cancer Group 12 trial. Eur Urol 73(6): 870-876, 2018. PMID: 29395502. DOI: 10.1016/j.eururo.2018.01.012

4 Fizazi K, Lesaunier F, Delva R, Gravis G, Rolland F, Priou F, Ferrero JM, Houedé N, Mourey L, Theodore C, Krakowski I, Berdah JF, Baciuchka M, Laguerre B, Fléchon A, Ravaud A, Cojean-Zelek I, Oudard S, Labourey JL, Lagrange JL, ChinetCharrot P, Linassier C, Deplanque G, Beuzeboc P, Geneve J, Davin JL, Tournay $\mathrm{E}$ and Culine S: A phase III trial of docetaxel-estramustine in high-risk localised prostate cancer: a planned analysis of response, toxicity and quality of life in the GETUG 12 trial. Eur J Cancer 48(2): 209-217, 2012. PMID: 22119204. DOI: 10.1016/j.ejca.2011.10.015

5 Sanda MG, Cadeddu JA, Kirkby E, Chen RC, Crispino T, Fontanarosa J, Freedland SJ, Greene K, Klotz LH, Makarov DV, Nelson JB, Rodrigues G, Sandler HM, Taplin ME and Treadwell JR: Clinically localized prostate cancer: AUA/ASTRO/SUO Guideline. Part I: Risk stratification, shared decision making, and care options. J Urol 199(3): 683-690, 2018. PMID: 29203269. DOI: $10.1016 /$ j.juro.2017.11.095

6 Mottet N, Bellmunt J, Bolla M, Briers E, Cumberbatch MG, De Santis M, Fossati N, Gross T, Henry AM, Joniau S, Lam TB, Mason MD, Matveev VB, Moldovan PC, van den Bergh RCN, Van den Broeck T, van der Poel HG, van der Kwast TH, Rouvière O, Schoots IG, Wiegel T and Cornford P: EAU-ESTRO-SIOG guidelines on prostate cancer. Part 1: Screening, diagnosis, and local treatment with curative intent. Eur Urol 71(4): 618-629, 2017. PMID: 27568654. DOI: 10.1016/j.eururo.2016.08.003

7 Briganti A, Karnes RJ, Gandaglia G, Spahn M, Gontero P, Tosco L, Kneitz B, Chun FK, Zaffuto E, Sun M, Graefen M, Marchioro G, Frohneberg D, Giona S, Karakiewicz PI, Van Poppel H, Montorsi F, Joniau S and European Multicenter Prostate Cancer Clinical and Translational Research Group (EMPaCT): Natural history of surgically treated high-risk prostate cancer. Urol Oncol 33(4): 163.e7-163.13, 2015. PMID: 25665508. DOI: 10.1016/ j.urolonc.2014.11.018 
8 Schaeffer E, Srinivas S, Antonarakis ES, Amstrong AJ, Bekelman JE, Cheng H, D'Amico AV, Davis BJ, Desai N, Dorff T, Eastham JA, Farrington TA, Gao X, Horwitz EM, Ippolito JE, Kuettel MR, Lang JM, McKay R, McKenney J, Netto G, Penson DF, Pow-Sang JM, Reiter R, Richey S, Roach III M, Rosenfeld S, Shabsigh A, Spratt DE, Teply BA, Tward J, Freedman-Cass D and Shead DA: NCCN clinical practice guidelines in oncology (NCCN guidelines $\left.{ }^{\circledR}\right)$ : Prostate Cancer. Version 2.2021. Available at: https://www.nccn.org/professionals/physician_gls/pdf/prostate.pdf [Last accessed on August 24, 2021]

9 Oudard S, Latorzeff I, Caty A, Miglianico L, Sevin E, HardyBessard AC, Delva R, Rolland F, Mouret L, Priou F, Beuzeboc P, Gravis G, Linassier C, Gomez P, Voog E, Muracciole X, Abraham C, Banu E, Ferrero JM, Ravaud A, Krakowski I, Lagrange JL, Deplanque G, Zylberait D, Bozec L, Houede N, Culine S and Elaidi R: Effect of adding docetaxel to androgendeprivation therapy in patients with high-risk prostate cancer with rising prostate-specific antigen levels after primary local therapy: a randomized clinical trial. JAMA Oncol 5(5): 623-632, 2019. PMID: 30703190. DOI: 10.1001/jamaoncol.2018.6607

10 Petrylak DP, Tangen CM, Hussain MH, Lara PN Jr, Jones JA, Taplin ME, Burch PA, Berry D, Moinpour C, Kohli M, Benson MC, Small EJ, Raghavan D and Crawford ED: Docetaxel and estramustine compared with mitoxantrone and prednisone for advanced refractory prostate cancer. N Engl J Med 351(15): 15131520, 2004. PMID: 15470214. DOI: 10.1056/NEJMoa041318

11 Tannock IF, de Wit R, Berry WR, Horti J, Pluzanska A, Chi KN, Oudard S, Théodore C, James ND, Turesson I, Rosenthal MA, Eisenberger MA and TAX 327 Investigators: Docetaxel plus prednisone or mitoxantrone plus prednisone for advanced prostate cancer. N Engl J Med 351(15): 1502-1512, 2004. PMID: 15470213. DOI: 10.1056/NEJMoa040720

12 Kellokumpu-Lehtinen PL, Harmenberg U, Joensuu T, McDermott R, Hervonen P, Ginman C, Luukkaa M, Nyandoto P, Hemminki A, Nilsson S, McCaffrey J, Asola R, Turpeenniemi-Hujanen T, Laestadius F, Tasmuth T, Sandberg K, Keane M, Lehtinen I, Luukkaala T, Joensuu H and PROSTY study group: 2-Weekly versus 3-weekly docetaxel to treat castration-resistant advanced prostate cancer: a randomised, phase 3 trial. Lancet Oncol 14(2): 117-124, 2013. PMID: 23294853. DOI: 10.1016/S1470-2045(12) $70537-5$

13 Sweeney CJ, Chen YH, Carducci M, Liu G, Jarrard DF, Eisenberger M, Wong YN, Hahn N, Kohli M, Cooney MM, Dreicer R, Vogelzang NJ, Picus J, Shevrin D, Hussain M, Garcia JA and DiPaola RS: Chemohormonal therapy in metastatic hormone-sensitive prostate cancer. N Engl J Med 373(8): 737746, 2015. PMID: 26244877. DOI: 10.1056/NEJMoa1503747

14 Kyriakopoulos CE, Chen YH, Carducci MA, Liu G, Jarrard DF, Hahn NM, Shevrin DH, Dreicer R, Hussain M, Eisenberger M, Kohli M, Plimack ER, Vogelzang NJ, Picus J, Cooney MM, Garcia JA, DiPaola RS and Sweeney CJ: Chemohormonal therapy in metastatic hormone-sensitive prostate cancer: Longterm survival analysis of the randomized Phase III E3805 CHAARTED trial. J Clin Oncol 36(11): 1080-1087, 2018. PMID: 29384722. DOI: 10.1200/JCO.2017.75.3657

15 Joensuu H, Kellokumpu-Lehtinen PL, Bono P, Alanko T, Kataja V, Asola R, Utriainen T, Kokko R, Hemminki A, Tarkkanen M, Turpeenniemi-Hujanen T, Jyrkkiö S, Flander M, Helle L, Ingalsuo S, Johansson K, Jääskeläinen AS, Pajunen M, Rauhala M, KalevaKerola J, Salminen T, Leinonen M, Elomaa I, Isola J and FinHer
Study Investigators: Adjuvant docetaxel or vinorelbine with or without trastuzumab for breast cancer. N Engl J Med 354(8): 809820, 2006. PMID: 16495393. DOI: 10.1056/NEJMoa053028

16 Martin M, Pienkowski T, Mackey J, Pawlicki M, Guastalla JP, Weaver C, Tomiak E, Al-Tweigeri T, Chap L, Juhos E, Guevin R, Howell A, Fornander T, Hainsworth J, Coleman R, Vinholes J, Modiano M, Pinter T, Tang SC, Colwell B, Prady C, Provencher L, Walde D, Rodriguez-Lescure A, Hugh J, Loret C, Rupin M, Blitz S, Jacobs P, Murawsky M, Riva A, Vogel C and Breast Cancer International Research Group 001 Investigators: Adjuvant docetaxel for node-positive breast cancer. N Engl J Med 352(22): 2302-2313, 2005. PMID: 15930421. DOI: 10.1056/NEJMoa043681

17 Early Breast Cancer Trialists' Collaborative Group (EBCTCG), Peto R, Davies C, Godwin J, Gray R, Pan HC, Clarke M, Cutter D, Darby S, McGale P, Taylor C, Wang YC, Bergh J, Di Leo A, Albain K, Swain S, Piccart M and Pritchard K: Comparisons between different polychemotherapy regimens for early breast cancer: meta-analyses of long-term outcome among 100,000 women in 123 randomised trials. Lancet 379(9814): 432-444, 2012. PMID: 22152853. DOI: 10.1016/S0140-6736(11)61625-5

18 Dumont C, Baciarello G, Bosset PO, Lavaud P, Colomba E, Massard C, Loriot Y, Albiges L, Blanchard P, Bossi A, Nenan S and Fizazi K: Long-term castration-related outcomes in patients with high-risk localized prostate cancer treated with androgen deprivation therapy with or without docetaxel and estramustine in the UNICANCER GETUG-12 trial. Clin Genitourin Cancer 18(6): 444-451, 2020. PMID: 32349927. DOI: 10.1016/j.clgc.2020.03.017

19 Esper P, Mo F, Chodak G, Sinner M, Cella D and Pienta KJ: Measuring quality of life in men with prostate cancer using the functional assessment of cancer therapy-prostate instrument. Urology 50(6): 920-928, 1997. PMID: 9426724. DOI: 10.1016/ S0090-4295(97)00459-7

20 FACT-P: Functional assessment of cancer therapy - prostate. For patients with prostate cancer. Available at: https://www.facit.org/ measures/FACT-P [Last accessed on May 15, 2021]

21 Cella D, Nichol MB, Eton D, Nelson JB and Mulani P: Estimating clinically meaningful changes for the Functional Assessment of Cancer Therapy - Prostate: results from a clinical trial of patients with metastatic hormone-refractory prostate cancer. Value Health 12(1): 124-129, 2009. PMID: 18647260. DOI: $10.1111 / \mathrm{j} .1524-4733.2008 .00409 . x$

22 Chvetzoff G and Tannock IF: Placebo effects in oncology. J Natl Cancer Inst 95(1): 19-29, 2003. PMID: 12509397. DOI: 10.1093/jnci/95.1.19

23 World Medical Association: World Medical Association Declaration of Helsinki: ethical principles for medical research involving human subjects. JAMA 310(20): 2191-2194, 2013. PMID: 24141714. DOI: 10.1001/jama.2013.281053

24 Krueger C and Tian L: A comparison of the general linear mixed model and repeated measures ANOVA using a dataset with multiple missing data points. Biol Res Nurs 6(2): 151-157, 2004. PMID: 15388912 . DOI: $10.1177 / 1099800404267682$

$25 \mathrm{Xi}$ W, Pennell ML, Andridge RR and Paskett ED: Comparison of intent-to-treat analysis strategies for pre-post studies with loss to follow-up. Contemp Clin Trials Commun 11: 20-29, 2018. PMID: 30023456. DOI: 10.1016/j.conctc.2018.05.008

Received October 20, 2021

Revised November 15, 2021

Accepted November 22, 2021 